\title{
A Case Of Postprtum Rcvs Failed To Respond To Metylprednisolon
}

Dr.M.Mehrpour MD,MPH , Dr.F.Haji Akhoundi MD, Dr.M.Afrakhteh MD, Dr.L.Raeesmohammadi MD, Dr.R.Ashyeri MD, Dr.M.Motamed MD,

\section{Introduction:}

Reversible cerebral vasoconstriction syndrome(RCVS) is a rare condition that occurs as the result of a sudden constriction(tightening) of the vessels that supply blood to the brain. the main symptom of RCVS is thunderclap headaches. stroke or bleeding in to the brain and seizure may or may not be present. the condition is more commonly diagnosed in women between the ages of 20 to 50 and may be associated with changes that happen in the body immediately after giving birth or changing birth control pills. other risk factors associated with RCVS include: use of drugs, alcohol, nicotin patches and certain tumors.

\section{Objective:}

For the first time in our center we diagnose and treat a postpartum RCVS.

\section{Case Description:}

A 37year old lady was referred to our center with GTCS and thunderclap headache. she had an uncomplicated cesarian section last week. she had no significant past medical history and her blood pressure was normal during pregnancy. drug history was negative. in physical exam blood pressure and neurologic exam were normal. in our assessment brain imaging showed cortical SAH, lab data including blood biochemistries and csf were normal, in Angiography vasospasm in left $A 1$ and in carotid duplex MCA velocity was $220 \mathrm{~cm} / \mathrm{s}$. Therefore we started nimodipin and metylprednisolon but her symptom aggravated and she showed increased MCA velocity in TCD.SO BRAIN Angiography was done for the second time that show generalized vasospasm in anterior circulation, bilateral $v 4$ and basilar arteries. nimodipin and milrinone were injected slowly and vasospasm become better.TCD monitoring showed decreased MCAs velocities and her symptom did not recur and in TCD MCAs PSVs were below $150 \mathrm{~cm} / \mathrm{s}$.

\section{Discussion:}

We presented a case of postpartum RCVS, that aggravated with intra venous metylprednisolon, and resolved with intra arterial milrinone. RCVS is a syndrome of cerebral arterial vasoconstriction, usually presenting with recurrent thunderclap headaches, seizures and focal neurologic deficits. our patient $s$ symptoms consist of a thunderclap headache and a GTCS. our patient was not a case of eclampsia and other predisposing factors of RCVS were also absent. she was one of the rare reported cases of RCVS in the postpartum period. treatment of RCVS in usually conservative and symptomatic cases. few existing trapeutic option include: oral or intra arterial of CCBs. Recent studies reported that steroids lack beneficial in RCVS and may even worsen vasoconstriction. this is what happened in our patient. She finally improved with intra arterial milrinone injection.

Key words: postprtum rcvs, metylprednisolon

DOI: 10.7575/aiac.abcmed.ca1.73

Published Date: February 2017

Peer-review is under responsibility of the 9th Iranian Stroke Congress.

Published by Australian International Academic Centre, Australia

This published work is open access under the CC BY license.

Available online at www.abcmed.aiac.org.au 